\title{
Numerical simulation of the inundation area for landslide-induced debris flow: a case study of the Sha-Xinkai gully in southern Taiwan
}

\author{
J.-C. Chen ${ }^{1}$, J.-S. Wang ${ }^{2}$, M.-R. Chuang ${ }^{1} \&$ C.-J. Jeng ${ }^{1}$ \\ ${ }^{I}$ Department of Environmental and Hazards-Resistant Design, \\ Huafan University, Taiwan \\ ${ }^{2}$ Ecological Soil and Water Conservation Research Centre, \\ National Cheng Kung University, Taiwan
}

\begin{abstract}
Typhoon Morakot struck central and southern Taiwan on August 8, 2009, and the high rainfall intensity and accumulated rainfall-induced several floods, landslides, and debris flows. In this study, the destructive debris flow caused by Typhoon Morakot in the Sha-Xinkai gully of the Liouguei District in southern Taiwan was selected as a case study for analysis. A two-dimensional model (FLO-2D software) was used to simulate debris flow. First, hydrological and geomorphological data were collected on the debris flow event and the rheological properties of slurry collected from the field were analyzed. Next, the relationship between debris flow discharge and water flow discharge was obtained. The simulation results for the deposited area and depth were then compared to aerial photos taken during a field investigation. Finally, the bulked coefficient of discharge and the resistant parameters used in the model were presented. The results showed that the maximum deposited depth in the debris flow inundated area was over $6 \mathrm{~m}$; the maximum velocity, $6.6 \mathrm{~m} / \mathrm{s}$; and the deposited volume, almost 1,000,000 $\mathrm{m}^{3}$. The simulated deposition depth and inundation area matched the results from the field investigation reasonably well. In this study, the parameters and processes needed for the simulation of landslide-induced debris flows were proposed to provide a reference for hazard zone mapping and debris flow hazard mitigation.
\end{abstract}

Keywords: Typhoon Morakot, FLO-2D, rheological property, bulked coefficient. 


\section{Introduction}

Typhoon Morakot struck central and southern Taiwan on August 8, 2009. The extreme rainfall (maximum hourly rainfall of $123 \mathrm{~mm}$ and 48 -h rainfall of 2,361 mm measured at the Alishan rainfall station) associated with the typhooninduced several landslides, debris flows, and floods (Chen et al. [1]; Wang et al. [2]). In the basin of the Raolung River in southern Taiwan, many landslideinduced debris flow hazards originate from a gully that has a small watershed area $(A)$ (e.g., $A$ smaller than 40 ha) and a high landslide ratio $\left(R_{L}\right)$ (e.g., $R_{L}>$ $30 \%$ where $R_{L}$ is the ratio of landslide area $A_{L}$ to watershed area $A$ or $R_{L}=$ $\left.A_{L} / A\right)$. Gullies with small watershed areas are generally unknown or overlooked by people, and they are often the cause of serious disasters during extreme rainfall events. The number of extreme rainfall events in Taiwan has increasing trend in recent years, which has resulted in a greater number and magnitude of debris flows during the last decade (Chen et al. [3]). Hence, the development of techniques that can identify and possibly prevent debris flows in gullies is a very important research topic for hazard mitigation efforts.

The FLO-2D [4] routing model is software designed for two-dimensional mathematical modeling of water movement and fast flowing slope processes including debris flows. The FLO-2D model has been used successfully for debris flow simulations by many researchers in a variety of countries (Lin et al. [5]; Tecca et al. [6]; Sosio et al. [7]; Stolz et al. [8]; Jakob and Weatherly [9]; Hsu et al. [10]; Sodnik and Mikos [11]). Data required for model simulations include a digital terrain model, an inflow hydrograph, rheological properties of the sediment water mixture, and the Manning roughness coefficient. The results from debris flow simulations are especially sensitive to the inflow hydrograph and rheological parameters associated with volumetric sediment concentrations. The inflow hydrograph may be underestimated for small watershed areas with high landside ratios. However, previous research has generally focused on debris flows from large watershed areas. Furthermore, the rheological parameters used in previous studies are usually determined by the back analysis method or by comparisons between model simulations and field observations. In contrast, the rheological parameters used in this study were determined via laboratory experiments. Two volumetric concentrations were used to simulate landslideinduced debris flow, and the empirical coefficient (i.e., the discharge bulked coefficient) that described the relationship between debris flow discharge and water flow discharge was determined in this study. Results of this study can provide a basic framework Results of this study can provide a basic framework for determining debris flow discharges and select rheological parameters in simulations of landslide-induced debris flows, which is important for hazard zone mapping and debris flow hazard mitigation. 


\section{Study area}

The Sha-Xinkai gully study area is located in the Shinfa Village of the Liouguei District, Kaoshing city, in southern Taiwan (Figure 1). It has a catchment area of $29.7 \mathrm{ha}$, a main stream length of $542 \mathrm{~m}$, and an average stream bed slope of $22.5^{\circ}$.

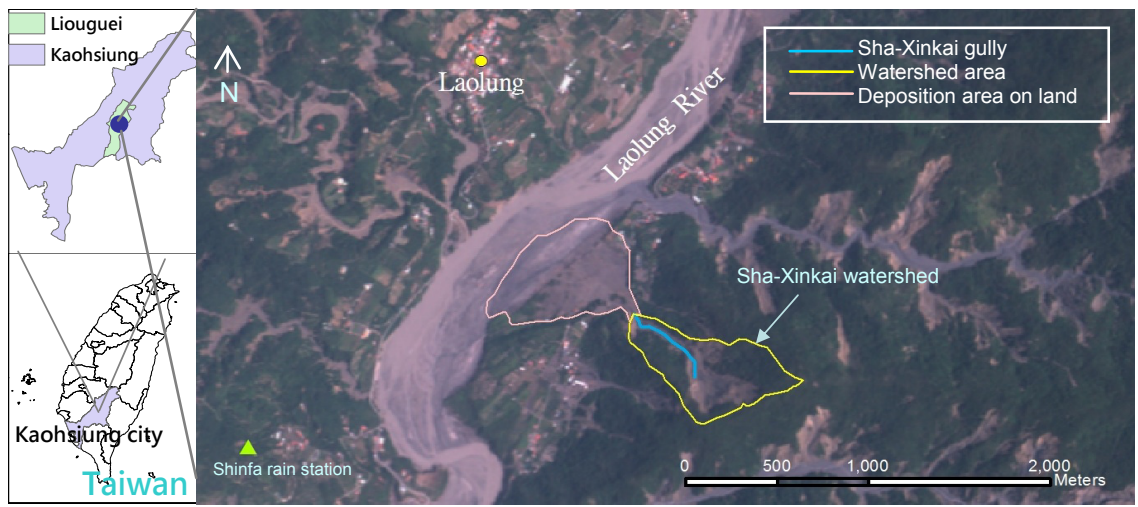

Figure 1: $\quad$ Location of the Sha-Xinkai gully, the Sha-Xinkai watershed, and the deposition of debris flow material during Typhoon Morakot in 2009.

\subsection{Debris flow hazard and rainfall}

\subsubsection{Debris flow hazard}

In 2009, Typhoon Morakot brought intense rainfall to southern Taiwan and caused many landslides and debris flows in the Shifa village. The Sha-Xinkai gully, a site of one of the landslide-induced debris flows in the village, was selected as our study area. The event resulted from a landslide that occurred upstream and entered the main stream of the gully where it mixed with water to become a debris flow. The debris flow eroded the sidewalls of the stream, which entrained additional material that traveled further downstream. In total, the ShaXinkai debris flow produced approximately 1,000,000 $\mathrm{m}^{3}$ of deposited sediments in downstream areas. The deposited depth was over $6 \mathrm{~m}$ in certain areas (SWCB [12]). The debris flow traveled downstream into the Shifa village and Laolung River where over 30 houses were buried. Tragically, the debris flow caused the death of four individuals, and 24 people were reported missing. The maximum deposition width on land approached $800 \mathrm{~m}$. The landslide area in the ShaXinkai watershed was 12.1 ha, and the landslide ratio was $40.7 \%$.

\subsubsection{Rainfall}

The hourly and cumulative rainfall data collected from the Shinfa rain gauge station, which is located approximately $2 \mathrm{~km}$ away from the Sha-Xinkai gully, 
during Typhoon Morakot is shown in Figure 2. An hourly maximum rainfall record of $103 \mathrm{~mm}$ was recorded at 6:00 PM on August 8, 2009. The 24-h rainfall maximum of $1200 \mathrm{~mm}$ occurred over a period lasting from 3:00 AM on August 8, 2009, to 3:00 AM on August 9, 2009. Debris flows subsequently occurred within the period of the 24-h rainfall maximum. The initial landslide and small debris flows began around 7:00 PM on August 8, 2009 at the time that the hourly rainfall reached its maximum amount. During 8:30 to 9:00 PM on August 8, 2009 , the debris flow greatly expanded in size, flowed downstream, and buried downstream areas in sediment.

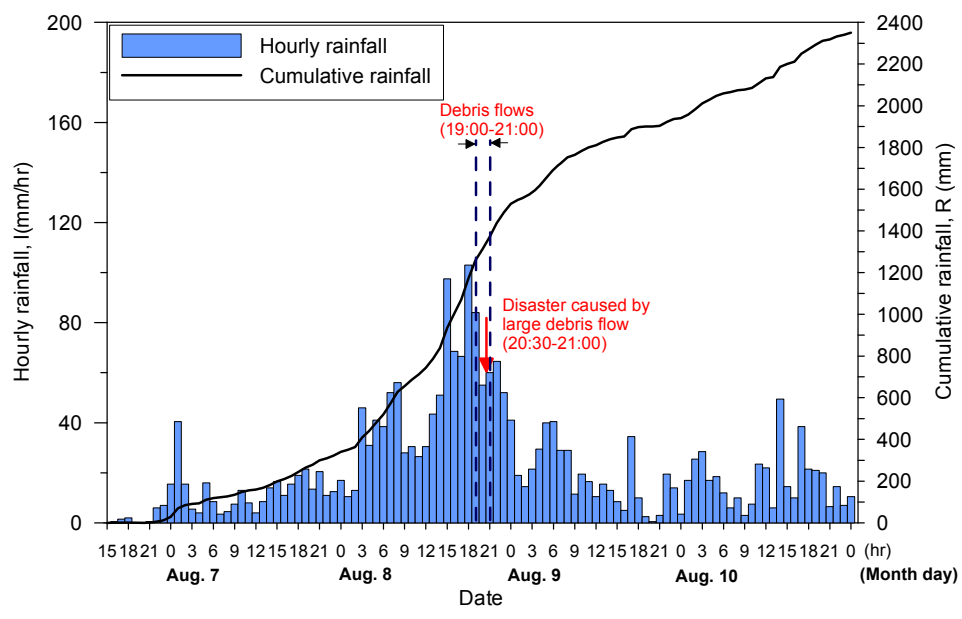

Figure 2: $\quad$ Rainfall data collected from August 7, 2009 to August 10, 2009 at the Shinfa rain gauge station and the time that a debris flow was triggered.

\subsection{Rheological properties}

Rheological properties are very important when modeling debris flows. In the FLO-2D model, the rheological parameters, including the mixture yield stress $\left(\tau_{y}\right)$ and the mixture viscosity $(\eta)$, are used to describe the rheological characteristics of debris flows. The rheological parameters are dependent on the volumetric concentration $\left(c_{V}\right)$, and they have a significant effect on debris flow processes and the final deposition morphology (FLO-2D [4]). To determine the rheological parameters of debris flow, soil samples with a particle diameter of less than $1 \mathrm{~mm}$ were collected from the flow area of the Hong-Shui-Xian gully, which is located next to the Sha-Xinkai debris flow. The soil samples were analyzed in a laboratory experiment using a Brookfield viscometer (type DV-III). The relationship between the shear stress and shear strain for the soil sample at various $c_{V}$ values was analyzed. The results showed that the rheological properties of the debris flow slurries could be described by the Bingham model. The Bingham model contains two rheological parameters: yield stress $\left(\tau_{y}\right)$ and 
viscosity $(\eta)$. The $\tau_{y}$ (in dynes $/ \mathrm{cm}^{2}$ units) and $\eta$ (in poise units) both exponentially increased with an increase in volumetric concentration $\left(C_{V}\right)$ (Figures 3 and 4), and these terms were defined as:

$$
\begin{aligned}
& \tau_{y}=0.459 e^{16.43 c_{r}} \\
& \eta=0.0485 e^{14.94 c_{v}}
\end{aligned}
$$

The results from Eqs. (1) and (2) were consistent with the bounds reported in previous studies (FLO-2D [4]; Dai et al. [13]; Fei [14]). Because the lithological characteristics and grain sizes of deposits in the Sha-Xinkai gully were almost identical to the Hong-Shui-Xian gully, the rheological relationships from Eqs. (1) and (2) were used to determine the rheological parameters for debris flow simulations in this study.

\section{Methods}

\subsection{FLO-2D model}

A two-dimensional commercial model, FLO-2D, which is physically based and takes into account the mass and momentum conservation of flows, was used to analyze the inundation area for landslide-induced debris flow in the Sha-Xinkai gully. The basic equations used in the FLO-2D model include the continuity equation and the dynamic equation. The inflow sediment concentration and the inflow hydrograph provide the input conditions for continuity equation routing, and the total shear stress involved in the dynamic equation affects the flow behavior. The parameters related to the total shear stress include the rheological parameters of yield stress $\left(\tau_{y}\right)$ and viscosity $(\eta)$, the resistant parameter of laminar flow $(k)$, and the Manning roughness coefficient $(n)$. These parameters affect the flow velocity, flow depth, and deposition area. The volumetric sediment concentration, inflow hydrograph, and the parameters related to flow resistance $\left(\tau_{y}, \eta, k\right.$, and $n$ ) should be determined prior to debris flow simulations.

\subsection{Simulation and analysis procedure}

\subsubsection{Preparation of topographic and rainfall data and selection of parameters}

Data required for the model simulation included a Digital Elevation Model (DEM), inflow hydrograph, and various parameters related to flow resistance such as $\tau_{y}, \eta, k$, and $n$. The parameters used in this work are described as follows:

1. Topographic data: Topographic input data were obtained from a DEM of the Sha-Xinkai watershed. The data had a resolution of $5 \mathrm{~m} \times 5 \mathrm{~m}$. 
2. Rainfall data: Rainfall data were collected from the Shinfa rain gauge station. The maximum hourly rainfall data from this station were used to determine peak water flow discharges in the Sha-Xinkai gully during Typhoon Morakot.

3. Parameters for simulation: The relationships for rheological parameters (Eqs. (1) and (2)) were used to simulate debris flow. In addition to the rheological parameters, other important parameters included the Manning roughness coefficient $(n)$ and the resistance parameter for laminar flow $(k)$. The $n$ value depends on the land surface, and it can be determined by referencing the FLO-2D user's manual [4]. In the Sha-Xinkai gully, the ${ }^{n}$ value ranged from 0.10 to 0.20 . Hence, a $n=0.15$ was adopted for use in this study. The $k$ value can range from 24 to 50,000. For modeling debris flow, a calibrated $k$ value of 2285 (FLO-2D [4]) was used to simulate the Sha-Xinkai debris flow event.

\subsubsection{Determination of debris flow discharge}

In engineering planning, debris flow discharge $\left(Q_{d p}\right)$ is generally considered to be directly related to direct runoff ( $\left.Q_{w p}\right)$ (Chen et al. [15]) so that $Q_{d p}$ is proportional to $Q_{w p}$ and can be expressed as:

$$
Q_{d p}=c_{b} Q_{w p}
$$

where $c_{b}$ is the discharge bulked coefficient. The value for $Q_{w p}$ is generally determined from the rational formula, $Q_{w p}=C I A / 360$, where $C$ is the runoff coefficient, $I$ is the maximum hourly rainfall intensity $(\mathrm{mm} / \mathrm{h})$, and $A$ is the watershed area. In the Sha-Xinkai gully study area, $C=0.8$ (SWCB [16]), $I=$ $103 \mathrm{~mm} / \mathrm{h}$ (i.e., the maximum hourly rainfall observed at the Shinfa rain gauge station during Typhoon Morakot), and $A=29.7$ ha. Hence, $Q_{w p}$ was $6.8 \mathrm{~m}^{3} / \mathrm{s}$ according to the rational formula described above. The discharge bulked coefficient $\left(c_{b}\right)$ depends on conditions of sediment supplementation. The $c_{b}$ value can be high when a watershed has a high landslide ratio or when there is high sediment supplementation. The debris flow discharge in this study was determined by Eq. (3), and the $c_{b}$ value was calibrated by comparing the results obtained from numerical simulations to those obtained in the field investigation.

\subsubsection{Construction of the inflow hydrograph for debris flow}

According to media reports and visits by residents, landslides and small debris flows began to occur around 7:00 PM on August 8, 2009. This escalated into a large and rapid debris flow event at approximately 8:30 to 9:00 PM that had disastrous consequences. Thus, the inflow hydrograph had a duration of approximately $2 \mathrm{~h}$ (7:00-9:00 PM). The duration of the inflow hydrograph was divided into two stages for this study. Stage one (from 7:00 to 8:30 PM) was the stage in which landslides gradually transferred to small debris flows and stage two (from 8:30 to 9:00 PM) was the stage of the large debris flow formation. The ranges of $c_{V}$ used for the two stages were obtained from reference values in 
the FLO-2D user's manual [4]. Stage one had a $c_{V}=0.55-0.65$ for landslides and stage two had a $c_{V}=0.48-0.55$ for debris flows. The inflow hydrograph used in this study is shown in Figure 3.

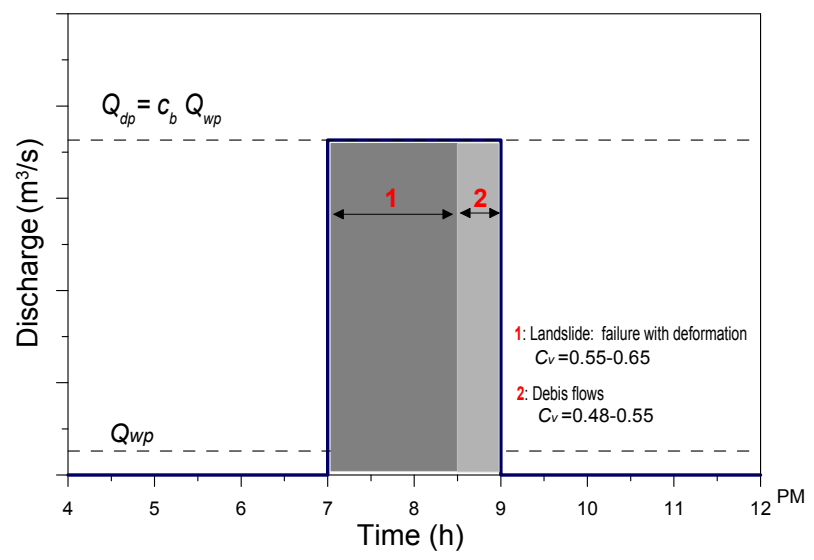

Figure 3: The inflow hydrograph used for this study. The hydrograph was divided into stages 1 and 2 for simulations of debris flow.

\subsubsection{Debris flow simulations and parameter calibration}

Since debris flow often impact downstream areas where the debris is ultimately deposited, modeling the depositional area of the debris flow was the primary interest of this paper. The procedures used for determining the depositional area of the debris flow and the calibration parameters $\left(c_{b}\right.$ and $\left.c_{V}\right)$ are described as follows:

1. Determine the location of the debris flow fan apex such as the mouth of the valley or the area downstream of the topographic apex. The location of the fan apex for the debris flow gully was obtained from topographical map and field investigations.

2. Assume a $c_{b}$ value and a set of $c_{V}$ values for determining the inflow hydrograph as indicated in Figure 3. Input the inflow hydrograph at the debris flow fan apex and the various parameters related to flow resistance such as $\tau_{y}$ (Eq. (1)), $\eta$ (Eq. (2)), $k(=2285)$, and $n(=0.15)$. The inundation area of the Sha-Xinkai debris flow was then computed through FLO-2D simulations. The results of FLO-2D simulations were compared to field conditions in terms of deposition depth and depositional area. If the simulated results were not in agreement with field conditions, the inflow conditions (i.e., $c_{b}$ and $c_{V}$ ) were adjusted until the simulated results were similar to the conditions observed in the field investigation. 


\section{Results}

\subsection{Discharge bulked coefficient}

If the water discharge contained in the debris flow discharge is solely contributed by direct runoff $\left(Q_{w p}\right)$ (i.e., water flow discharge), the debris flow discharge ( $Q_{d p}$ ) is directly related to $Q_{w p}$, and it is equivalent to the sum of $Q_{w p}$ and the sediment discharge $\left(Q_{s}\right)$ (where $Q_{s}=c_{V} Q_{d p}$ ). The discharge bulked coefficient $\left(c_{b}\right)$ in Eq. (3) can be expressed as:

$$
c_{b}=\left(1-c_{V}\right)^{-1}
$$

Similar to Eq. (4), Takahashi [17] derived $c_{b}=\left(1-k_{c}^{*} c_{V}\right)^{-1}$ for debris flows generated from gully bed erosion where $k_{c}{ }^{*}=c_{*}{ }^{-1}$ and $c_{*}$ is the volumetric concentration of the sediment layer on the gully bed. The maximum $c_{V}$ values observed ranged up to $0.9 c$. (Takahashi [17]). Based on Takahashi's research, the maximum $c_{b}=10$ if $c_{V}=0.9 c_{*}$. This implies that the maximum debris flow discharge is 10 times that of the water flow discharge. However, in the relationships for $c_{b}=\left(1-c_{V}\right)^{-1}$ or $c_{b}=\left(1-k_{c}^{*} c_{V}\right)^{-1}$, ground water or the water contained in the sediment layer was not considered. Hence, the $c_{b}$ value calculated by $c_{b}=\left(1-c_{V}\right)^{-1}$ or $c_{b}=\left(1-k_{c}^{*} c_{V}\right)^{-1}$ may underestimate the discharge for debris flows induced by large landslides. The peak water flow discharge $\left(Q_{w p}\right)$ determined by the rational formula in this case study was $6.8 \mathrm{~m}^{3} / \mathrm{s}$. Here, the $c_{V}$ value was calculated by the relationship of the equilibrium concentration (Takahashi [17]):

$$
c_{V}=\frac{\tan \theta}{\left(G_{s}-1\right)(\tan \phi-\tan \theta)}
$$

where $G_{s}$ is the specific gravity; $\phi$, the friction angle; and $\theta$, the angle of the gully bed in flow section. Using a $G_{s}=2.65, \phi=35^{\circ}$, and $\theta=17^{\circ}$, the $c_{V}$ value determined from Eq. (5) was $c_{V}=0.47$. Also, the $c_{b}=1.89$ according to Eq. (4). These data imply that the debris flow discharge was 1.89 times that of the water flow discharge $\left(Q_{d p}=1.89 Q_{w p}\right)$. The inundation area was modeled using an inflow hydrograph of debris flow discharge of $Q_{d p}=16.2 \mathrm{~m}^{3} / \mathrm{s}\left(1.89 Q_{w p}\right)$, a duration of $2 \mathrm{~h}$, and the rheological parameters (i.e., $\tau_{y}$ and $\mu_{b}$ ) computed with Eqs. (1) and (2). Additionally, a $c_{V}=0.47, n=0.15$, and $k=2285$ were used as inputs. Figure 4 shows the inundation area of debris flow from the FLO-2D simulations. The inundation area and deposition depth from the simulations were smaller than those determined from the field investigation due to an underestimation of debris flow discharge. Besides direct runoff, the water flow that initiated the debris flow likely came from ground water or water contained in sediments that was brought in by the landslides. Furthermore, water flow could have been blocked by the sediment brought in by landslides, which would have rapidly increased water storage in the watershed. When the stored water combined with sediments burst over a short period of time, this could have led to 
a high debris flow discharge. The $c_{b}$ value calculated with Eq. (3) ranged from 15 to 20 when the inflow hydrograph followed the type shown in Figure 3 and the debris flow volume was estimated at $1,000,000 \mathrm{~m}^{3}$. The $c_{b}$ value in the study area was calibrated by comparisons of the numerical simulations to field investigation data.

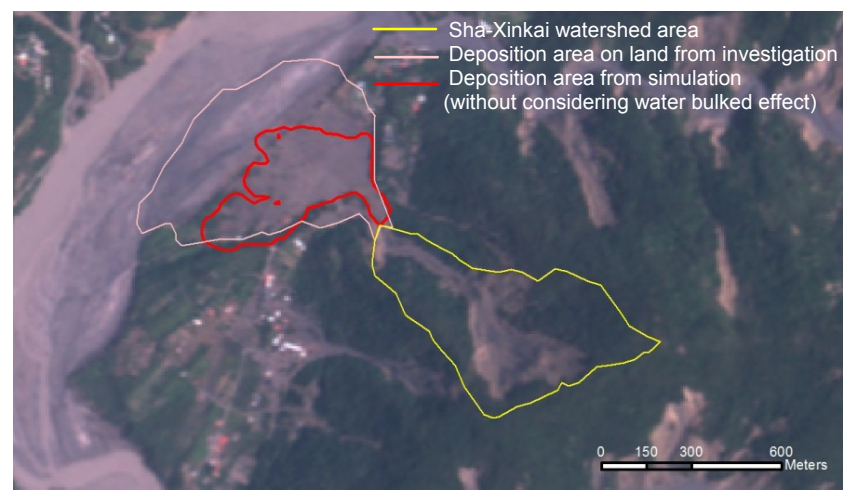

Figure 4: $\quad$ Comparison of the simulated versus actual debris flow inundated area. The simulated debris flow was determined using an inflow hydrograph with a discharge bulked coefficient $c_{b}=1.89$. The $c_{b}$ attributed to landslides was not considered here.

\subsection{Parameter calibration}

When $n=0.15, c_{b}=18$, and the $c_{V}$ values for stages one and two were 0.64 and 0.50 , respectively, in the inflow hydrograph (Figure 3 ), the depositional area and deposition depth from the simulations were close to those observed during the field investigation (Figure 5). The deposited depth in the debris flow

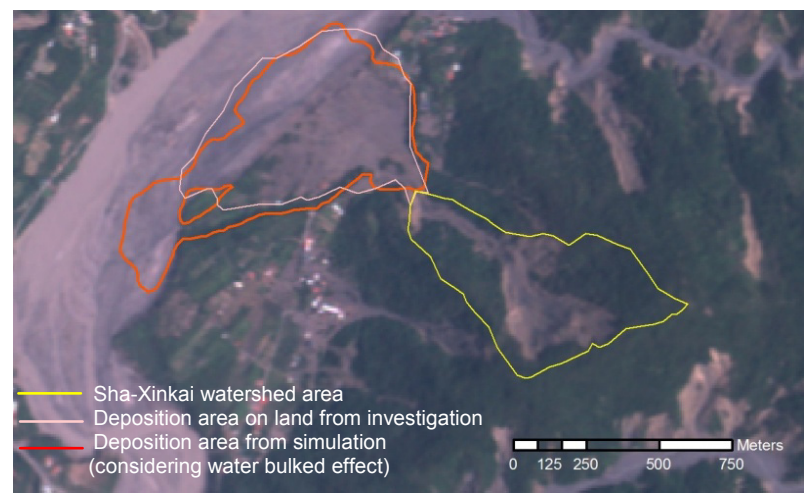

Figure 5: The simulated depositional area after adjustments were made based on field data. 
inundated area was over $6 \mathrm{~m}$. The debris flow discharge was 18 times that of the peak water flow discharge due to the high landslide ratio $(40.7 \%)$ in the ShaXinkai gully. The simulated results also showed that the debris flow rapidly inundated the downstream area at 8:30-9:00 PM on August 8, 2009, with a maximum velocity of $6.6 \mathrm{~m} / \mathrm{s}$.

\section{Conclusions}

The study area in the Sha-Xinkai debris flow gully had a small watershed area ( $A$ ) and a high landslide ratio $\left(R_{L}\right)\left(A=29.7\right.$ ha and $\left.R_{L}=40.7 \%\right)$. For this type of the debris flow gully, the peak water discharge computed from the rational formula was small and it likely underestimated the inflow hydrograph in debris flow simulations. The depositional area and deposition depth in the simulations were strongly affected by the inflow hydrograph that was associated with the discharge bulked coefficient $\left(c_{b}\right)$ and the volumetric concentration $\left(c_{V}\right)$. A method to reasonably determine $c_{b}$ and $c_{V}$ is important for debris flow simulation research. In this study, the relationship between debris flow discharge ( $\left.Q_{d p}\right)$, peak water flow discharge ( $Q_{w p}$ ) (or $c_{b}$ value), and $c_{V}$ values in the inflow hydrograph were calibrated by comparing the results obtained from the numerical simulations to data from a field investigation. The debris flow discharge in the Sha-Xinkai gully had a $Q_{d p}=18 Q_{w p}$ or $c_{b}=18$. Two $c_{V}$ values for two different stages of the hydrograph were used to evaluate rheological parameters (yield stress $\tau_{y}$ and viscosity $\eta$ ), and these values were $c_{V}=0.64$ and 0.50 for stages one and two, respectively. Calculation results also indicated that the simulated sediment volume was approximately $1,000,000 \mathrm{~m}^{3}$, the maximum flow velocity was about $6.6 \mathrm{~m} / \mathrm{s}$, and the maximum depth on the flow was over $6 \mathrm{~m}$. The simulated average depth was close to the depth observed in the field investigation. These data may useful as a reference for future hazard zone mapping and debris flow hazard mitigation.

\section{References}

[1] Chen, T. C., Wu, C. C., Weng, M. C., Hsieh, K. H. \& Wang, C.C., Slope Failure of Lawnon Basin Induced by Typhoon Morakot, Sino-Geotechnics, 122, pp. 13-20, 2009 (in Chinese).

[2] Wang, C.M., Lee, S.P., Li, C.C., Tsang, Y.C. \& Shieh, C.L., Disasters caused by Typhoon Morakot, Journal of the Taiwan Disaster Prevention Society, 2(1), pp. 27-34, 2010 (in Chinese).

[3] Chen, J.C., Huang, W. S., Jan, C.D. \& Yang, Y.H., Recent Changes in the Number of Rainfall Events Related to Debris-Flow Occurrence in the Chenyulan Stream Watershed, Taiwan, Nat. Hazards Earth Syst. Sci., 12, pp. 1539-1549, 2012.

[4] FLO-2D, FLO-2D Users Manual, Ver. 2009. FLO-2D Software Inc, Nutrioso, AZ, USA, 2009. 
[5] Lin, M.L.,Wang, K.L. \& Huang, J.J., Debris flow run off simulation and verification - case study of Chen-You-Lan Watershed, Taiwan., Nat. Hazards Earth Syst. Sci., 5, pp. 439-445, 2005.

[6] Tecca, P.R., Genevois, R., Deganutti, A.M., \& Armento, M.C., Numerical modelling of two debris flows in the Dolomites (Northeastern Italian Alps)., Debris-Flow Hazards Mitigation: Mechanics, Prediction, and Assessment, Chen \& Major, eds, Millpress, Netherlands, pp. 179-188, 2007.

[7] Sosio, R., Crosta, G.B. \& Frattini, P., Field observations, rheological testing and numerical modelling of a debris-flow event. Earth Surf. Process. Landforms, 32, pp. 290-306, 2007.

[8] Stolz, A. \& Huggel, C., Debris flows in the Swiss National Park: the influence of different flow models and varying DEM grid size on modeling results. Landslides, 5, pp. 311-319, 2008.

[9] Jakob, M. \& Weatherly, H., Integrating uncertainty: Canyon Creek hyperconcentrated flows of November 1989 and 1990., Landslides, 5, pp. 83-95, 2008.

[10] Hsu, S. M., Chiou, L. B., Lin, G. F., Chao, C. H., Wen, H. Y. \& Ku, C. Y., Applications of simulation technique on debris-flow hazard zone delineation: a case study in Hualien County. Taiwan, Nat. Hazards Earth Syst. Sci., 10, pp. 535-545, 2010.

[11] Sodnik, J. \& Mikos, M., Estimation of magnitudes of debris flows in selected torrential watersheds in Slovenia, Acta geographica Slovenica, 46(1), pp. 93-123, 2006.

[12] SWCB, Disasters caused by Typhoon Morakot in Taiwan, 1999. Soil and Water Conservation Bureau (SWCB), Taiwan, 2009 (in Chinese)

[13] Dai, J., et al., An experimental study of slurry transport in pipes. Proc., Int. Symposium on River Sedimentation, pp. 195-204, 1980.

[14] Fei, X. J., Bingham yield stress of sediment water mixtures with hyperconcentration, J. Sediment Res., 3, Beijing, China, pp. 19-28, 1981.

[15] Chen, J.C., Jan, C.D., and Lee, M.S., Reliability Analysis of Design Discharge for Mountainous Gully Flow, Journal of Hydraulic Research, 46(6), pp. 835-838, 2008.

[16] SWCB, Technical Handbook of Soil and Water Conservation, Soil and Water Conservation Bureau (SWCB), Taiwan, 2005. (in Chinese)

[17] Takahashi, T., Debris Flow. IAHR Monograph. Balkema, Rotterdam, 1999. 